\title{
Aplicando o Método Percurso com Barreiras: indo além da avaliação automática de acessibilidade
}

\author{
Hélio Braga ${ }^{1}$, Letícia Seixas Pereira ${ }^{1}$, Simone Bacellar Leal Ferreira ${ }^{1}$, \\ Denis Silva da Silveira ${ }^{2}$
}

\author{
${ }^{1}$ Programa de Pós-Graduação em Informática - PPGI \\ UNIRIO - Universidade Federal do Estado do Rio de Janeiro \\ Avenida Pasteur, 458, Urca, CEP: 22290-040, Rio de Janeiro - RJ - Brasil \\ ${ }^{2}$ Programa de Pós-Graduação em Administração - PROPAD \\ UFPE - Universidade Federal de Pernambuco \\ Av. dos Funcionários, s/n, Cidade Universitária, CEP: 50740-580, Recife - PE, Brasil \\ \{helio.braga, leticia.pereira, simone\}@uniriotec.br, dsilveira@ufpe.br
}

\begin{abstract}
Over the years, people suffer changes caused by the aging of the body and might develop some kind of visual, hearing, motor, among others dysfunctions. These limitations may represent difficulties to access services provided by the Internet, which are growing increasingly. This work is an assessment of accessibility of Internet banking service of the Banco do Brasil using the Method Barrier Walkthrough. The application of this technique made it possible to identify, evaluate and suggest improvements to diminish the obstacles that hinder and/or make it impossible for the elderly users to perform tasks on this website.

Resumo. Com o passar dos anos, as pessoas sofrem mudanças causadas pelo envelhecimento, podendo obter algum tipo de deficiência visual, auditiva, motora, entre outras. Essas limitações podem representar dificuldade para o acesso a serviços prestados pela Internet, que vem crescendo cada vez mais. Nesse trabalho é realizada uma avaliação de acessibilidade do serviço de Internet Banking do Banco do Brasil utilizando o Método de Percurso de Barreiras. Com a aplicação dessa técnica foi possível identificar, avaliar o impacto e sugerir melhorias quanto a barreiras que dificultam elou impossibilitam a execução de tarefas por usuários idosos nesse site.
\end{abstract}

\section{Introdução}

A população na terceira idade representa uma parcela crescente da população e possui uma participação econômica ativa na sociedade [IBGE 2010]. Os países em desenvolvimento estão apresentando índices de envelhecimento tão altos quanto os países desenvolvidos, chegando até a superá-los em alguns casos. No Brasil, os efeitos do envelhecimento da população já começam a serem sentidos e terão um impacto ainda maior dentro dos próximos anos [Esteves e Slongo 2012].

Atualmente, já se constata que a terceira idade faz parte de um mercado em expansão não só do ponto de vista populacional, como também econômico, representando um imenso potencial merecendo, portanto, uma maior atenção por parte 
dos pesquisadores [Esteves e Slongo 2012]. Diante desse cenário, tornar aplicações na Internet acessíveis a essa categoria de usuários torna-se cada vez mais necessário.

Acessibilidade na web é a característica que torna possível a qualquer pessoa, independente de sua condição, a qualquer hora, local, dispositivo utilizado e ambiente, ter acesso às informações e/ou serviços web [Spelta 2003]. Usabilidade é a característica que determina se o manuseio de um produto é fácil, não provoca erros operacionais, oferece alto grau de satisfação para o usuário, é simples de ser aprendido e dificilmente esquecido [Nielsen 2006]. uma aplicação orientada à usabilidade não significa necessariamente que é orientada a acessibilidade e vice-versa [Hanson 2004].

Mesmo tendo como base diretrizes de acessibilidade, tais como WCAG (Web Content Accessibility Guidelines) e e-MAG (Modelo de Acessibilidade de Governo Eletrônico), entre outras, o desenvolvimento de sistemas acessíveis é um desafio para os designers, uma vez que usuários diferentes possuem necessidades diferentes e as soluções podem eventualmente ser conflitantes. Essa situação ocorre no caso de usuários idosos, que frequentemente possuem uma série de deficiências a serem consideradas, em virtude das transformações físicas e cognitivas decorrentes da idade. [Hanson 2001].

Para determinar se as interfaces, parte do sistema que os usuários interagem para executarem suas tarefas, são acessíveis é necessário realizar uma avaliação de acessibilidade. Uma das formas de avaliação é através do uso de ferramentas automáticas, que no entanto, não é capaz de identificar problemas de usabilidade com foco em acessibilidade para categorias específicas de usuários. As próprias diretrizes determinam que para considerar uma interface acessível, a verificação automática não é suficiente, sendo necessários também testes com humanos, tanto como especialistas como com usuários com limitações [W3C 2013]. Além disso, as ferramentas de avaliação automática ainda não são capazes de avaliar conteúdo gerado dinamicamente, sendo possível apenas avaliar estas páginas utilizando amostras [Fortes et al.2005].

Mas realizar observações com a participação de usuários não é fácil; dentre as complexidades desse processo encontra-se a dificuldade de obter voluntários com disponibilidade para realizar os testes, representando um obstáculo na acessibilização completa dos sistemas [Ferreira et al. 2007].

Diante dessas dificuldades, e considerando-se o aumento da população de idosos no Brasil e a oferta de serviços essenciais disponibilizados aos cidadãos através da Internet, o presente trabalho teve por finalidade avaliar a acessibilidade e as barreiras presentes no acesso à funcionalidades do Internet Banking do Banco do Brasil utilizando o método de Percurso de Barreiras, que relaciona e descreve um conjunto de barreiras que são sensíveis para cada categoria de usuários [Brajnik 2012], tornando possível manter o foco da avaliação em usuários idosos. $\mathrm{O}$ objetivo dessa pesquisa foi verificar se esse método pode ser utilizado como complemento à avaliação automática, quando não for possível realizar observações envolvendo usuários.

\section{Internet Banking}

O Internet Banking é uma modalidade de comércio eletrônico, disponibilizado pelos bancos na Internet, através da qual seus clientes podem realizar várias operações financeiras, tais como: pagamentos, transferências de dinheiro entre contas, descontos, 
empréstimos, etc. [Estrada, 2005]; com essa tecnologia, os serviços bancários podem ser acessados de qualquer lugar a qualquer hora, bastando apenas ao cliente ter acesso à Internet [Silva et al. 2006].

O uso do Internet Banking traz várias vantagens aos Bancos e seus clientes, tais como: redução de custos para manutenção de agências, especificamente nas despesas de pessoal; desburocratização de serviços; dispensa a presença física do cliente nas agências; redução de filas; aumento do alcance geográfico, através da Internet, podendo fornecer serviços em grande escala; diminuição de riscos de assaltos, pois há um menor movimento de pessoas, moeda e serviços nas agências. $\mathrm{O}$ uso do Internet Banking vem se popularizando cada vez mais, representando $23 \%$ do total de suas transações bancárias em 2010 sendo o segundo canal mais utilizado pelos clientes [Febrabran 2011]. A função mais utilizada é a de consulta de saldo/extrato com 79\%. Em segundo lugar ficam os pagamentos, sendo utilizados por $60 \%$ e por fim as transferências e Doc's (Documento de Ordem de Crédito) - usadas por 44\% [Estrada 2005].

Quanto à percepção dos usuários do Internet Banking, em uma pesquisa feita por [Estrada 2005], 10\% dos entrevistados revelou que utilizaria mais o serviço se alguém o ensinasse a usar. Além disso, $46 \%$ revelou que sente falta de atendimento online e $42 \%$ gostariam também de um canal de contato direto com seu gerente por e-mail.

\section{Terceira Idade (Idosos)}

Segundo o Estatuto do Idoso (Lei 10.741, de $1^{\circ}$ de outubro de 2003) são considerados idosos pessoas com idade igual ou superior a 65 anos. Já a Organização Mundial da Saúde (OMS) considera como idosas as pessoas com 60 anos ou mais, se elas residem em países em desenvolvimento, e com 65 anos e mais se residem em países desenvolvidos [OMS 2013].

O envelhecimento é um processo que se inicia desde a concepção, onde ocorrem diversas alterações nos órgãos, células e tecidos, e são associadas à mudanças psicoemocionais. Aos 65 anos de idade, $50 \%$ das pessoas podem experimentar alguma deficiência em algum grau e um quarto da população pode enfrentar alguma deficiência grave [Hanson 2001]. O envelhecimento sem um doença crônica é uma exceção, entretanto isso não deve representar uma razão para exclusão social, ainda mais considerando que os idosos permanecem ativos na sociedade [IBGE 2010]. Segundo [Garcia 2001], é necessário compreender as limitações impostas pelo envelhecimento para reinserir os idosos nas relações sociais que atualmente são pautadas pelas novas tecnologias. Algumas deficiências comuns na terceira idade e no uso da Internet podem ser enumeradas como: visão, destreza motora e problemas cognitivos [Hanson 2001].

\section{Métodos de Avaliação de Acessibilidade}

Uma avaliação de interfaces é um processo sistemático de coleta de dados para analisar como os usuários executam suas tarefas através de algum artefato de ambiente computacional. Através dessas avaliações é possível identificar problemas de usabilidade e acessibilidade do sistema [Bach et al. 2009; Ferreira et al. 2012]. Os métodos de avaliação podem ser classificados como inspeção e observação do uso. Os métodos de avaliação que não exigem a presença dos usuários são chamados de "métodos de inspeção ou métodos analíticos ou prognósticos". Aqueles que são feitos 
com a presença de usuários são chamados de "métodos de observação ou testes com os usuários" [Barbosa e Silva 2010].

Uma avaliação pode ser feita através de ferramentas automáticas que verificam se as interfaces estão em conformidade com as diretrizes de acessibilidade, gerando relatórios com a lista dos problemas que devem ser corrigidos para que a interface seja considerável acessível. Em geral, os problemas de usabilidade relacionados à acessibilidade podem ser classificados como: $i$ ) muito foco na conformidade com as diretrizes de acessibilidade e não em usabilidade; ii) desconsideração dos aspectos de usabilidade em decorrência da dependência das técnicas de verificação sistemáticas dos sites limitada a camada das tags; iii) avaliadores desconsideram o fato de que os usuários se movimentam pelas páginas usando combinações de teclas e criam desta forma seus modelos mentais [Takagi 2004].

\subsection{Método de Percurso de Barreiras}

Um método de inspeção de interfaces que procura identificar problemas de acessibilidade é o Percurso de Barreiras (barrier walkthrough) [Brajnik 2006]. Uma barreira é uma condição que dificulta as pessoas de atingirem seus objetivos quando navegam por um site [Brajnik 2012]. As possíveis barreiras são previamente levantadas e se baseiam em interpretações e extensões de princípios de acessibilidade bem conhecidos e podem ser descritas em termos da categoria do usuário envolvido, o tipo de tecnologia de apoio utilizada, o objetivo que está impactado, características das páginas onde são encontradas e os efeitos provocados. Para cada categoria de usuário, há uma lista de barreiras potenciais que podem ser verificadas nas páginas Web [Brajnik 2009]. [Lunn et al. 2009] analisou as orientações existentes na literatura sobre os efeitos do envelhecimento e produziu uma lista de barreiras enfrentadas por idosos.

Para aplicar o método de Percurso de Barreiras, o avaliador deve identificar cenários compostos por tipos de usuários, configurações, objetivos e possíveis tarefas [Tanaka 2010]. É importante considerar também as possíveis barreiras previamente listadas para uma categoria de usuário em um contexto para que conclusões adequadas a respeito da eficácia, produtividade, satisfação e segurança dos usuários possam ser feitas e definir o grau de severidade da barreira naquele cenário [Brajnik 2006].

Recomenda-se que os objetivos e tarefas que serão inspecionados pelo método sejam extraídos das especificações dos casos de uso, de maneira que cada tarefa/objetivo tenha um conjunto de interfaces diferentes ou ainda, um percurso de interfaces a ser seguido [Tanaka 2010]. O avaliador segue o percurso estabelecido e dado uma categoria de usuário, identifica se existem barreiras nas interfaces associadas que dificultem o atendimento do objetivo ou a execução das tarefas estabelecidas.

De acordo com o método, a barreira, logo que encontrada, deve ter seu grau de severidade atribuído, determinado de acordo com o impacto, ou seja, o grau de comprometimento do objetivo pelo usuário dentro do cenário determinado, e a persistência, que de traduz no número de vezes em que a barreira surge enquanto o usuário tenta atingir o objetivo inicial. $\mathrm{O}$ grau de severidade da barreira pode ser classificado entre os valores 1 e 3 (menor, maior e crítico), conforme a Tabela 1 . O grau do impacto varia de 0 a 3 , onde zero significa que a barreira não foi identificada, 1 a barreira não interferiu significativamente na execução da tarefa, 2 a barreira afeta moderadamente a execução da tarefa, obrigando o usuário a transpô-la e 3, a barreira 
impede o avanço na execução da tarefa obrigando o usuário a buscar alternativas para atingir seu objetivo, ou ainda impede que o usuário atinja seu objetivo [Brajnik 2012].

Para cada barreira identificada, um grau de impacto deve ser atribuído. O grau de impacto é interpretado pelo avaliador considerando quanto do desempenho do usuário na execução da tarefa é afetado. Segundo o método, o desempenho do usuário pode ser avaliado considerando os seguintes atributos [Brajnik 2012]: Eficácia: capacidade de atingir com precisão os objetivos; Produtividade: tempo, esforço, recursos e carga cognitiva que são necessárias para atingir algum nível de eficácia; Satisfação: facilidade de uso, produtividade e segurança percebida pelo usuário; Segurança: segurança pessoal e financeira. Ao final de uma inspeção, os avaliadores devem se reunir e produzir uma lista dos problemas encontrados associando um grau de severidade para cada um deles, de acordo com a Tabela 1.

Tabela 1. Tabela grau de severidade das barreiras [Brajnik 2012]

\begin{tabular}{|c|c|c|}
\hline Impacto & Persistência & Severidade \\
\hline 1 & 1 & Menor \\
\hline 1 & 2 & Menor \\
\hline 1 & $\Rightarrow 3$ & Significante \\
\hline 2 & 1 & Significante \\
\hline 2 & 2 & Significante \\
\hline 2 & $\Rightarrow 3$ & Critica \\
\hline 3 & 1 & Crítica \\
\hline 3 & 2 & Critica \\
\hline 3 & $\Rightarrow 3$ & Critica \\
\hline
\end{tabular}

\section{Trabalhos Anteriores}

Foram encontrados dois trabalhos na literatura, porém nenhum realizou uma avaliação de acessibilidade em sistemas de Internet Banking, com foco em usuários idosos e com um método aliado à avaliação automática e os testes finais com o usuário.

Em [Prado 2010] foi realizado um trabalho com objetivo de avaliar a qualidade de 12 Websites de Internet Banking através da identificação dos fatores mais importantes e relevantes para a determinação do conceito de qualidade nesse contexto e, da identificação de grupos de usuários relacionados por definição e percepções de qualidade em relação a um Website. Para o estudo foi desenvolvido um modelo de variáveis mensurando a percepção de qualidade dos Websites pelo usuário. Através da análise realizada com um questionário estruturado como coleta de dados, observou-se que as qualidades mais destacadas foram a usabilidade e o tempo de resposta, ligada aos usuários mais jovens, e a facilidade de uso, destacada pelos usuários mais velhos.

Em [Sales e Cybis 2003] foi apresentado um checklist para verificação da conformidade de páginas Web de acordo com recomendações específicas de acessibilidade para usuários idosos. Por meio de um subconjunto de critérios elaborados através das capacidades sensoriais e funcionais desses usuários foi criado um checklist como ferramenta de avaliação $W e b$. Para a validação da pesquisa foram realizadas duas avaliações de acessibilidade em interfaces utilizando o artefato criado.

\section{Método de Pesquisa}

A presente pesquisa, de caráter exploratório, foi realizada em quatro etapas: a) Escolha do método e da técnica de avaliação; b) Execução da avaliação; c) Análise dos resultados e d) Elaboração de recomendações. 
a) Escolha do método e a técnica de avaliação: foi utilizado o método de Percurso de Barreiras [Brajnik 2006] e uma lista de potenciais barreiras para usuários idosos [Lunn et al.2009], resumida na Tabela 2. Essa escolha levou em consideração a dificuldade da aplicação de uma validação automática nas funcionalidades do site do Internet Banking e das vantagens em relação à revisão de conformidade com as diretrizes de acessibilidade (guidelines), ao fornecer uma lista de barreiras para a categoria de usuários idosos, mantendo o foco no tipo de usuário de interesse do estudo, e por utilizar cenários de uso, orientando a avaliação pela execução de tarefas e objetivos de interesse do usuário.

b) Execução da avaliação: Foram selecionadas as seguintes tarefas para serem inspecionadas: a) Interface principal; b) Acessar a conta bancária; c) Consultar saldo da conta; d) Consultar extrato bancário; e) Realizar pagamento por boleto bancário.

A avaliação foi feita alunos em Sistemas de Informação de um Programa mestrado de uma Universidade Federal no Estado do Rio de Janeiro e não utilizou especialistas em acessibilidade e/ou usuários. As tarefas escolhidas foram executadas pelos avaliadores observando se alguma das barreiras existentes na planilha para coleta de dados da avaliação da Figura 1 ocorria. Quando uma barreira era identificada os avaliadores interpretavam e informavam seu grau de impacto na tarefa e o número de vezes que surgia. A partir dessas informações, o grau de severidade era derivado, conforme Tabela 1. Para cada barreira, os avaliadores informavam detalhes da sua interpretação e dos graus atribuídos.

Ao término da avaliação, os avaliadores se reuniram para revisar em conjunto os resultados coletados. Nessa revisão os avaliadores apresentaram suas interpretações em relação às barreiras identificadas buscando consenso quanto aos graus de severidade atribuídos. Ainda nesse encontro, os avaliadores discutiram a respeito das melhorias que poderiam ser feitas para eliminar ou reduzir os impactos das barreiras conforme as orientações da lista de potenciais barreiras para idosos de [Lunn et al. 2009].

Para coletar os dados da avaliação foi elaborada uma planilha com as tarefas a serem inspecionadas e para cada tarefa, a lista de barreiras para a categoria de usuários idosos [Lunn et al. 2009]. Para cada barreira deveriam ser informados o grau de impacto, a persistência, severidade e detalhes considerados na avaliação, de acordo com a Figura 1.



Figura 1. Fragmento da Planilha Utilizada na Coleta dos Dados da Avaliação.

Tabela 2. Barreiras Pré-Existentes para Usuários Idosos [Lunn et al. 2009].

\section{Barreiras Perceptíveis}

Em relação ao Princípio Perceptível, O WCAG 2.0 define seu conceito e seu uso como: "Componentes de interface de usuário com informação e devem ser apresentadas aos usuários de forma que possam ser percebidas" [Caldwell et al. 2008]. Isso significa que todo o conteúdo de uma interface deve estar disponível para o usuário, independente de qualquer 


\begin{tabular}{|c|c|}
\hline \multicolumn{2}{|r|}{ I ou a tecnologia de apoio que possa ser usada } \\
\hline $\begin{array}{l}\text { Baixo } \\
\text { contraste de } \\
\text { cores }\end{array}$ & $\begin{array}{l}\text { Causa: Com o passar dos anos, pode-se observar diferentes graus de } \\
\text { sensibilidade ao contraste, reduzindo sua capacidade de distinção entre } \\
\text { cores similares - com baixo contraste. } \\
\text { Falha: Possível dificuldade na leitura do conteúdo em interfaces com baixo } \\
\text { contraste. }\end{array}$ \\
\hline $\begin{array}{l}\text { Falta de } \\
\text { coerência no } \\
\text { uso de cores }\end{array}$ & $\begin{array}{l}\text { Causa: A interface contém material, tais como texto, imagens, fundo e } \\
\text { vídeos, onde a cor é usada como único meio para distinguir entre dois ou } \\
\text { mais elementos de informação diferentes. } \\
\text { Falha: O usuário não tem como diferenciar os itens com as informações } \\
\text { necessárias. }\end{array}$ \\
\hline $\begin{array}{l}\text { Uso de fontes } \\
\text { pequenas }\end{array}$ & $\begin{array}{l}\text { Causa: Nos idosos, ocorre uma redução na visão, afetando a capacidade } \\
\text { de leitura em textos com fontes pequenas. Além disso, fontes menores, } \\
\text { dificultam o acesso a um link, pois muitas vezes os movimentos precisos do } \\
\text { mouse são dificultados pelo desenvolvimento de artrite. } \\
\text { Falha: Páginas com fontes pequenas podem impedir a leitura de textos e } \\
\text { acesso à hiperlinks. }\end{array}$ \\
\hline $\begin{array}{l}\text { Complexidad } \\
\text { e dos textos }\end{array}$ & $\begin{array}{l}\text { Causa: A interface contém textos de difícil compreensão pela complexidade } \\
\text { e/ou estrutura das frases, palavras, texto com excesso de siglas e } \\
\text { abreviaturas, ou ainda por erros de ortografia. } \\
\text { Falha: O usuário poderá ter dificuldade para entender o conteúdo. }\end{array}$ \\
\hline $\begin{array}{l}\text { Imagem sem } \\
\text { texto } \\
\text { equivalente }\end{array}$ & $\begin{array}{l}\text { Causa: A interface contém imagens que fornecem informações mas apenas } \\
\text { em formato gráfico, sem descrição textual equivalente. Idosos podem não } \\
\text { compreender a mensagem contida nas imagens e podem fazer uso do } \\
\text { texto alternativo para entender. Além disso, esses usuários podem utilizar } \\
\text { tecnologias assistivas, como leitores de tela, para acessar as interfaces em } \\
\text { áudio. Se as imagens não possuem essa descrição, a tecnologia assistiva } \\
\text { não será capaz de renderizar as imagens em áudio. } \\
\text { Falha: Mesmo que um idoso perceba que há uma imagem importante, pode } \\
\text { não ser capaz de entender a informação que ela contém. }\end{array}$ \\
\hline $\begin{array}{l}\text { Uso de } \\
\text { conteúdo } \\
\text { animado }\end{array}$ & $\begin{array}{l}\text { Causa: Uso de imagens ou textos em movimento - GIF's animados, } \\
\text { banners em flash etc. } \\
\text { Falha: O usuário pode não ser capaz de perceber que o conteúdo foi } \\
\text { alterado, não conseguindo ler rápido o suficiente para interagir com o } \\
\text { conteúdo ou ainda perder o foco das principais informações }\end{array}$ \\
\hline \multicolumn{2}{|c|}{$\begin{array}{l}\text { Barreiras Operacionais } \\
\text { Em relação ao Princípio Operável, O WCAG } 2.0 \text { define que os componentes de interface e } \\
\text { navegação devem ser operáveis, portanto, os usuários devem ser capazes de operar todos } \\
\text { os itens da interface, incluindo widgets e hiperlinks, independente de qualquer deficiência } \\
\text { sensorial ou tecnologia assistiva utilizada [Caldwell et al. 2008]. }\end{array}$} \\
\hline $\begin{array}{l}\text { Hiperli } \\
\text { botões } \\
\text { próxi }\end{array}$ & $\begin{array}{l}\text { Causa: A interface contém uma sequência de links com pouco } \\
\text { espaçamento entre os itens no sentido vertical ou horizontal. } \\
\text { Falha: Ao usar o mouse o usuário pode deslizar e acionar elementos } \\
\text { errados. }\end{array}$ \\
\hline $\begin{array}{l}\text { Hiperlinks e } \\
\text { botões muito } \\
\text { pequenos }\end{array}$ & $\begin{array}{l}\text { Causa: A interface contém links e botões muito pequenos. } \\
\text { Falha: O usuário pode enfrentar dificuldades em usar o mouse para clicar } \\
\text { em hiperlinks ou botões muito pequenos. }\end{array}$ \\
\hline $\begin{array}{r}\text { Hiperlir } \\
\text { tex } \\
\text { descr }\end{array}$ & $\begin{array}{l}\text { Causa: Hiperlinks que não possuem descrição adequada podem confundir } \\
\text { o usuário no entendimento da interface para onde será conduzido. } \\
\text { Falha: Ao ter que clicar em um hiperlink para finalizar uma tarefa o usuário } \\
\text { tende a mostrar sinais de hesitação. }\end{array}$ \\
\hline ue & Causa: A interface contém menus hierárquicos em cascata, onde as \\
\hline
\end{tabular}




\begin{tabular}{|c|c|}
\hline $\begin{array}{c}\text { menus em } \\
\text { cascata }\end{array}$ & $\begin{array}{l}\text { entradas de um menu acionam um menu de segundo nível. } \\
\text { Falha: O usuário pode ter dificuldades para mover corretamente o ponteiro } \\
\text { do mouse sobre as entradas desejadas, abrir menus secundários e mantê- } \\
\text { los abertos enquanto tenta levar o ponteiro do mouse para o item desejado. }\end{array}$ \\
\hline $\begin{array}{l}\text { Uso de } \\
\text { menus } \\
\text { dinâmicos em } \\
\text { Javascript }\end{array}$ & $\begin{array}{l}\text { Causa: Idosos podem ter problemas em movimentar o mouse, } \\
\text { especialmente quando exige precisão. } \\
\text { Falha: A interação com menus dinâmicos pode ser prejudicada em } \\
\text { consequência da possível dificuldade de movimentos precisos com o } \\
\text { mouse. Com isso, essa funcionalidade pode ficar comprometida. }\end{array}$ \\
\hline $\begin{array}{l}\text { Uso de } \\
\text { interações } \\
\text { baseadas em } \\
\text { eventos de } \\
\text { mouse }\end{array}$ & $\begin{array}{l}\text { Causa: A interface contém ações que são invocadas com funções a partir } \\
\text { de eventos do mouse, gerando comportamentos específicos. } \\
\text { Falha: Idosos podem ter dificuldade no controle do mouse e usarem } \\
\text { apenas o teclado para certas atividades. No entanto, os tratamentos de } \\
\text { evento do mouse podem criar uma situação onde a funcionalidade parece } \\
\text { estar disponível mas não funciona, pois não foi acionada corretamente. }\end{array}$ \\
\hline $\begin{array}{l}\text { Falta de } \\
\text { orientações e } \\
\text { dicas de } \\
\text { navegação } \\
\end{array}$ & $\begin{array}{l}\text { Causa: Os idosos podem adquirir deficiências cognitivas leves que afetam } \\
\text { o desempenho de suas tarefas, possuindo problemas para manter a sua } \\
\text { localização e posição dentro de uma interface. } \\
\text { Falha: Os usuários ficar perdidos e confusos para completar a tarefa. }\end{array}$ \\
\hline $\begin{array}{l}\text { Complexidad } \\
\text { e e falta de } \\
\text { atalhos de } \\
\text { navegação }\end{array}$ & $\begin{array}{l}\text { Causa: Muitos idosos sofrem com a perda de memória de curto prazo. A } \\
\text { exploração de interface com conteúdos dispostos em hierarquias } \\
\text { complexas e profundas pode ser um desafio para esses usuários. } \\
\text { Falha: Os idosos podem ficar perdidos e confusos para completar a tarefa }\end{array}$ \\
\hline $\begin{array}{l}\text { Abertura de } \\
\text { nova janela }\end{array}$ & $\begin{array}{l}\text { Causa: Ao acionar um botão ou link, a interface abre novas janelas no } \\
\text { navegador. } \\
\text { Falha: Ao abrir uma nova janela, o contexto de interação muda, alterando o } \\
\text { conteúdo e o conjunto de comandos e controles. Enquanto o usuário } \\
\text { executa uma tarefa, inesperadamente, uma nova janela é aberta, sendo } \\
\text { frustrante para o usuário. Muitas vezes, essas janelas são pop-ups com } \\
\text { conteúdos irrelevantes para a conclusão doe seu objetivo. Nessas janelas, } \\
\text { o botão de voltar do navegador não redireciona para a página anterior. }\end{array}$ \\
\hline $\begin{array}{l}\text { Abertura de } \\
\text { nova janela } \\
\text { sobreposta }\end{array}$ & $\begin{array}{l}\text { Causa: Ao acionar determinado botão ou link, a interface abre novas } \\
\text { janelas sobrepondo a janela atual, cobrindo-a toda ou completamente. } \\
\text { Falha: O usuário não distingue a nova janela da aberta anteriormente e } \\
\text { portanto, pode não identificar o novo contexto de interação, incluindo a } \\
\text { mudança de conteúdo, layout, hiperlinks, botões e controles de formulário. }\end{array}$ \\
\hline $\begin{array}{l}\text { Excesso de } \\
\text { rolagem da } \\
\text { interface }\end{array}$ & $\begin{array}{l}\text { Causa: Quando o conteúdo da interface ou imagens são maiores do que o } \\
\text { tamanho da tela, o usuário tem que deslocar a barra de rolagem para cima } \\
\text { e para baixo, ou da esquerda para a direita. } \\
\text { Falha: Pode ser difícil para um usuário ler uma interface em que precisa } \\
\text { deslocar o conteúdo constantemente além de dificultar seu entendimento }\end{array}$ \\
\hline $\begin{array}{l}\text { Imagens } \\
\text { incluídas na } \\
\text { interface de } \\
\text { fundo }\end{array}$ & $\begin{array}{l}\text { Causa: Muitas vezes informações são incluídas como plano de fundo nas } \\
\text { interfaces em formato de imagem, podendo causar confusão na interface, } \\
\text { confundindo e distraindo os usuários. } \\
\text { Falha: A confusão do usuário pode acarretar a não conclusão da tarefa. }\end{array}$ \\
\hline \multicolumn{2}{|c|}{$\begin{array}{l}\text { Barreiras de Compreensão } \\
\text { Em relação ao Princípio Compreensível, o WCAG } 2.0 \text { define que a informação para a } \\
\text { operação na interface do usuário deve ser compreensível [Caldwell et al. 2008]. Os usuários } \\
\text { devem ser capazes de compreender todas as informações e conteúdos presentes na } \\
\text { interface, independente de qualquer deficiência sensorial ou tecnologia assistiva utilizada. }\end{array}$} \\
\hline $\begin{array}{l}\text { Navegação e } \\
\text { layout } \\
\text { inconsistente } \\
\text { s }\end{array}$ & $\begin{array}{l}\text { No caso de idosos com capacidade cognitiva reduzida, a habilidade de } \\
\text { realizar tarefas pela primeira vez pode ficar comprometida. Ao navegar por } \\
\text { sites com layouts inconsistentes sentem dificuldades, pois não podem } \\
\text { referenciar a ação atual a uma experiência prévia. } \\
\text { Falha: A interação com as páginas pode se tornar mais estressante, além }\end{array}$ \\
\hline
\end{tabular}




\begin{tabular}{|c|c|}
\hline & $\begin{array}{l}\text { de aumentar o tempo de interação para realizar uma tarefa, devido a } \\
\text { constante necessidade de aprendizagem entre as páginas. }\end{array}$ \\
\hline $\begin{array}{l}\text { Falta de } \\
\text { agrupamento } \\
\text { de conteúdos } \\
\text { relacionados }\end{array}$ & $\begin{array}{l}\text { Causa: Usuários com memória reduzida possuem dificuldade de lembrar } \\
\text { listas de palavras relacionadas. } \\
\text { Falha: A informação distribuída pelo site aumenta a demanda da } \\
\text { capacidade cognitiva dos usuários. Isso pode retardar a taxa de conclusão } \\
\text { da tarefa, uma vez que o usuário precisa gastar mais tempo para identificar } \\
\text { informações e determinar se essa informação é relevante para a sua tarefa. }\end{array}$ \\
\hline $\begin{array}{l}\text { Excesso de } \\
\text { informação } \\
\text { exposta }\end{array}$ & $\begin{array}{l}\text { Causas: Em usuários idosos verifica-se dificuldade em buscas visuais, } \\
\text { principalmente em telas complexas. Com o excesso de informação exibida } \\
\text { nas páginas, os usuários se tornam mais propensos a distrações e erros. } \\
\text { Falha: Conteúdo desnecessário na mesma interface causa distração e } \\
\text { podem levar a um menor desempenho na execução da tarefa. }\end{array}$ \\
\hline $\begin{array}{l}\text { Complexidad } \\
\text { e em dados } \\
\text { tabulares }\end{array}$ & $\begin{array}{l}\text { Causa: Excesso de números de colunas e linhas em tabelas contidas. } \\
\text { Falha: O usuário pode enfrentar dificuldades em identificar a informação } \\
\text { desejada, e associar ao conteúdo de uma linha. Além disso, pode haver } \\
\text { dificuldades no entendimento das informações que requerem a } \\
\text { comparação de diferentes linhas e/ou colunas. }\end{array}$ \\
\hline $\begin{array}{l}\text { Página com } \\
\text { cintilar ou } \\
\text { piscar de } \\
\text { conteúdo }\end{array}$ & $\begin{array}{l}\text { Causa: A interface contém elementos, tais como imagens, textos ou } \\
\text { fundos, que piscam ou criam efeitos de flash a uma taxa entre } 3 \mathrm{~Hz} \text { a } 60 \mathrm{~Hz} \text {. } \\
\text { Falha: Em usuários com epilepsia fotossensível, a página pode } \\
\text { desencadear ataques epiléticos [Acção Epilepsia 2009]. }\end{array}$ \\
\hline
\end{tabular}

\section{c) Análise de resultados}

A lista de barreiras utilizada como referência estava bem definida, simplificando o processo de identificação das barreiras durante a execução das tarefas. O método escolhido fez com que a avaliação fosse executada com foco nos usuários idosos, evitando a avaliação de outros elementos que não fossem os de interesse da pesquisa.

Em relação aos critérios de impacto e persistência, foram encontradas diferentes interpretações, resultando em níveis de severidade distintos. Considerando esse grau de subjetividade, ficou evidente a relevância do uso da técnica de avaliação conjunta sugerida pelo método. Porém a identificação das barreiras críticas foi consistente entre os avaliadores. Comparando as avaliações, as barreiras do grupo operacional foram as que apresentaram o maior número de discrepância em relação aos graus de severidade, porém foram as que apresentaram a maior concordância quanto à criticidade. As avaliações apontaram várias barreiras para idosos na execução das tarefas no site de Internet Banking do Banco do Brasil. Das 115 barreiras avaliadas nas 5 interações, $36,5 \%$ foram classificadas como críticas, $16,5 \%$ consideradas significativas e $6 \%$ de menor severidade. Do total, $41 \%$ das barreiras não foram identificadas.

$\mathrm{Na}$ interface principal foram encontradas 14 barreiras, sendo 10 críticas, 3 significativas, 1 menor e as outras 9 não foram identificadas. $\mathrm{O}$ tamanho das fontes utilizadas e a ausência de textos alternativos nas imagens foram as barreiras classificadas como críticas. No grupo operacional, onde foram encontradas seis barreiras consideradas críticas, os hiperlinks apresentaram problemas quanto à distância entre eles e não possuíam textos explicativos. O uso de menus dinâmicos em Javascript e interações baseadas em eventos de mouse também foram classificados como barreiras críticas. Quanto ao grupo de barreiras de compreensão, foram identificados o excesso de informação exposta no layout da página e navegação inconsistente.

$\mathrm{Na}$ avaliação da tarefa acessar a conta foram identificadas 15 barreiras, sendo 9 críticas, 4 significativas, 2 menores e 8 não identificadas. Na execução dessa tarefa, o 
uso da fonte pequena foi apontado como barreira crítica. As cores utilizadas nos textos eram muito parecidas com a cor do fundo da página, dificultando a leitura. O grupo de barreiras operacionais identificados na interface principal foi novamente encontrado e, nas barreiras de compreensão, o excesso de informação também foi observado.

Em relação à avaliação da tarefa consultar saldo, foram encontradas 7 barreiras críticas, 3 significativas, 1 menor e 12 não foram identificadas. As barreiras operacionais encontradas na interface principal também se repetiram nessa tarefa, apresentando textos com fontes pequenas, informações e opções em excesso.

$\mathrm{Na}$ avaliação da tarefa consultar extrato bancário, das 23 barreiras analisadas, 9 não foram identificadas. Do grupo de barreiras perceptíveis foram encontradas 2 de severidade menor e 4 críticas, incluindo o tamanho da fonte utilizada, baixo contraste e falta de coerência no uso das cores e uso de texto complexo para exibir as opções ao gerar o extrato bancário, objetivo da tarefa. Como nas tarefas anteriores, as barreiras operacionais identificadas se repetiram e nas barreiras de compreensão, repetiu-se o excesso de informação com grau de severidade crítica.

$\mathrm{Na}$ tarefa realizar pagamento por boleto bancário, a avaliação revelou 7 barreiras críticas e 7 severas. $\mathrm{O}$ baixo contraste de cores e as fontes pequenas foram observados e considerados críticas. Foram identificadas como barreiras operacionais críticas os hiperlinks próximos, botões pequenos, menus dinâmicos em Javascript e uso de interações baseadas em eventos de mouse. Mais uma vez, o excesso de informações exposta foi uma barreira de compreensão avaliada como crítica.

A interface principal obteve o maior número de barreiras críticas, as quais se repetiram em quase todas as tarefas. $O$ excesso de informação exposta, uma das barreiras de compreensão, ocorreu em todas as tarefas avaliadas. As barreiras de uso de fontes pequenas, hiperlinks e botões muito próximos e muito pequenos, uso de menus dinâmicos em Javascript e uso de eventos de mouse foram frequentes, ocorrendo em quase todas as tarefas avaliadas. Isso pode ser um indício de falha na concepção do projeto em sua estrutura, fazendo com que as barreiras se propagassem em todas as interações verificadas no sistema. A maioria das barreiras avaliadas como críticas estão relacionadas à operação das interfaces, que afetam diretamente os objetivos do usuário ao acessarem o sistema.

\section{d) Elaboração de Recomendações}

A lista de barreira que afetam usuários idosos elaborada por [Lunn et al. 2009] apresenta, junto com as definições da barreira, recomendações para evitá-las. Desta forma, as recomendações de ajustes têm origem no método, facilitando a sua aplicação.

A maioria das pessoas, com o passar dos anos, acaba por desenvolver algum tipo de problema relacionado à visão. Por isso é recomendado o uso de fontes grandes, como $12 \mathrm{pt}$, e é necessário também que as páginas que possuam recursos como um link para aumentar o tamanho do texto, sejam diagramadas a fim de permitir a leitura correta do conteúdo, independente do tamanho de fonte escolhido pelo usuário [Lunn et al. 2009].

Como os idosos em geral apresentam movimentos mais lentos e imprecisos e, uma possível barreira para esses usuários é o uso de hiperlinks e botões, muitas vezes localizados próximos um do outro e/ou possuindo uma área destinada ao clique muito reduzida. Isso pode acarretar certa dificuldade de acesso ou erros na navegação e, pode 
ser evitado garantindo que esses elementos possuam uma área maior para clique do mouse, ou estejam separados por um espaço em branco para ajudar na distinção dos elementos e no acesso mesmo quando o mouse for utilizado com baixa precisão. Para melhorar o desempenho de navegação com botões, a medida desses itens deve estar em torno de 180 x 22 pixels [Lunn et al. 2009].

No que diz respeito ao uso de menus dinâmicos, opções e comandos criados através do Javascript, estes devem ser passíveis de serem selecionados mesmo quando essa tecnologia não está habilitada, ou seja, quando a opção de desabilitar o Javascript estiver marcada, todos os recursos deverão estar disponíveis. Além disso, para garantir o acesso aos recursos disparados por ações de mouse, deverão ser criados efeitos similares através de manipuladores lógicos de eventos, como onfocus ou onkeypress [Lunn et al. 2009]. Esses atributos foram projetados para serem independentes de dispositivo, sendo disparados através do teclado, mouse ou através de outras interfaces [W3C 2013].

Para uso de menus, é incentivado a implementação de menus planos através da listagem ordenada dos hiperlinks. É desencorajado os menus em cascata implementados através de Javascript e CSS (Cascading Style Sheets) [Lunn et al. 2009].

É possível também observar nos idosos algum nível de déficit de atenção. Por isso, os elementos presentes na interface, tais como imagens, banners e hiperlinks, devem ser revistos a fim de não confundir usuários, trazendo a atenção dos mesmos apenas para as informações relevantes da interface [Lunn et al. 2009].

\section{Limitações da pesquisa}

Apesar da técnica adotada na presente pesquisa ser objetiva quanto à verificação da existência das barreiras, a avaliação de acessibilidade seria mais assertiva se contasse com a participação de usuários. A ausência das especificações dos casos de uso também pode ser considerada um limitador, uma vez que os avaliadores inferiram, através do seu conhecimento prático, o percurso para a execução das tarefas.

\section{Considerações Finais}

O método de Percurso de Barreiras foi considerado adequado para a avaliação de acessibilidade do sistema de Internet Banking do Banco do Brasil, uma vez que permitiu que a avaliação ocorresse focada nas dificuldades enfrentadas pelos usuários idosos ao utilizarem as funcionalidades propostas sem, no entanto, exigir a participação dos usuários. A aplicação do método nas principais funções do sistema sob o ponto de vista do usuário idoso revelou um conjunto de barreiras críticas que podem afetar potencialmente a eficácia, a produtividade e satisfação dessa categoria de usuários.

Com o uso do método foi possível identificar de forma sistemática problemas de usabilidade relacionados à acessibilidade e propor recomendações. Com as dificuldades na utilização da verificação automática, o método permitiu uma avaliação rápida e objetiva, reduzindo a complexidade na realização da avaliação.

Finalmente, conclui-se que as interfaces das tarefas avaliadas do serviço de Internet Banking do Banco do Brasil, poderiam ser reformuladas a fim de melhorar o acesso para os usuários idosos. Como continuidade desse estudo, poderão ser realizadas novas avaliações utilizando o mesmo método, contando com um grupo maior de avaliadores, a fim de estudar os efeitos das divergências e convergências de resultados 
obtidos. Além disso, pode ser observada também a aplicabilidade das listas de barreiras por categorias de usuários como referências na obtenção de requisitos não funcionais relacionados à acessibilidade do desenvolvimento de interfaces web.

\section{Referências}

Bach, C. F.; Ferreira, S. B. L.; Silveira, D. S. (2009) Avaliação de Acessibilidade na Web: Estudo Comparativo entre Métodos de Avaliação com a Participação de Deficientes Visuais. In: XXXIII Encontro Nacional dos Programas de Pós Graduação em Administração - ENANPAD, São Paulo.

Barbosa, S. D. J.; Silva, B. S. (2010) Interação Humano-Computador. Rio de Janeiro: Elsevier.

Brajnik, G. Barrier Walkthrough: Heuristic evaluation guided by accessibility barriers. Disponível em: <http://sole.dimi.uniud.it/ giorgio.brajnik/projects/bw/bw.html> Acesso em 11 de nov. 2012.

Brajnik, G. (2006) Ranking websites through prioritized web accessibility barriers. In: Technology and Persons with Disabilities Conference, 2007, Los Angeles.

Caldwell, B.; Cooper, M.; Reid, L. G.; Vanderheiden, G. Web Content Accessibility Guidelines (WCAG) 2.0. 2008. Disponível em: < http://www.w3.org/TR/WCAG20/> Acesso em 8 de abril de 2013.

Esteves, P. S.; Slongo, L. A. (2012) A Internet e a Terceira Idade: Elaboração de um Modelo Teórico para a Compreensão deste Comportamento de Consumo, V Encontro de Marketing da ANPAD, Curitiba/Paraná.

Estrada, M. M. P. (2005) A Internet Banking no Brasil, na América Latina e na Europa. Revista do Programa de Mestrado em Direito do UniCEUB, Brasília.

Ferreira, S. B. L; Santos, R. C.; Silveira, D. S. (2007) Panorama da Acessibilidade na Web Brasileira. Revista de Controle e Administração (RCA) - Controladoria Geral do Rio de Janeiro - v. III, n. 2, p. 206-235 - jul./dez. 2007.

Ferreira, S. B. L; Silveira, D. S.; Capra, E. (2012) Protocols for Evaluation of Site Accessibility with the Participation of Blind Users. Proceedings of the 4th international conference on software development for enhancing accessibility and fighting info-exclusion (DSAI 2012), 2012 -Porto, Portugal.

Fortes, R. P. M.; Lara, S. M. A.; Freire, A. P.; Pansanato, L. T. E. (2005) Capítulo 7: Acessibilidade no Projeto de Aplicações Web. In: Teixeira, A. C.; Barrére, E.; Abrão, I. C. (Org.). Web e Multimídia: Desafios e Soluções. 1 ed. Poços de Caldas, MG: PUC Minas.

Garcia, H. D. (2001) A 3a idade e a Internet: uma questão para o novo milênio. Dissertação de Mestrado em Ciência da Informação.Universidade Estadual Paulista.

Hanson, V. L. (2001) Web Access for Elderly Citizens. Proceedings of the 2001 EC/NSF workshop on Universal accessibility of ubiquitous computing: providing for the elderly (WUAUC'01). ACM, NY, EUA.

Hanson, V. L. (2004) The User Experience: Designs and Adaptations. ACM Proceedings of International Cross-Disciplinary Workshop on Web-Pg:1-11.

IBGE. Síntese dos Indicadores Sociais- Uma análise das condições de vida da população brasileira - 2010

Lunn, D.; Yesilada, Y.; Harper, S. (2009) Barriers faced by older users on static web pages: criteria used in the barrier walkthrough method. University of Manchester, UK.

Nielsen, J.; Loranger, H. (2006) Prioritizing Web usability. Indianápolis - New Riders.

Prado, E. P. V. (2010) Sites de Internet Banking: Uma Avaliação da Qualidade Baseada no Modelo WebQual. Gestão e Regionalidade, v. 26, n.77, maio/agosto 2010.

Sales, M. B.; Cybis. W. A. (2003) Checklist para Avaliação de Acessibilidade de Interfaces Web para Usuários Idosos. Anais do II Seminário ATIID, São Paulo - SP.

Silva, J. P. Da; Oliveira, A. N. F. De; Bertoldo, M. O.; Neto, F. L. Dos S.; Florentino, R. V.; Costa, A. P. M. da. (2006) Internet Banking. Revista de Informática Aplicada, v. 2, n. 02, jul./dez. 2006. 
Spelta, L. L. (2003) O papel dos leitores de tela na construção de sites acessíveis. In: ATIID (Acessibilidade, Tecnologia da Informação e Inclusão Digital), São Paulo.

Takagi, H.; Asakawa, C.; Fukuda, K.; Maeda, J. (2004) Accessibility Designer: Visualizing Usability for the Blind. ASSETS'04, Atlanta, Georgia, USA.

Tanaka, E. H. (2009) Método Baseado em Heurísticas para Avaliação de Acessibilidade em SIção. Tese Doutorado . Universidade Estadual de Campinas, Instituto de Computação, Campinas, SP.

World Health Organization. Definition of an older or elderly person. Disponível em: <http://www.who.int/healthinfo/survey/ageingdefnolder/en/>Acesso em:1 dez. 2012.

W3C. Web Content Accessibility Guidelines (WCAG). Disponível em: <http://www.w3.org/TR/WCAG/>. Acesso em: 25 jan. 2013. 